\title{
The role of stakeholders in managing polythene and plastic waste in coastal cities of Sri Lanka: a case study of the Dehiwala-Mt. lavinia municipal council region
}

\author{
Suresh Kariyawasam ${ }^{1}$, Ayesha Madhuwanthi ${ }^{2}$, and Clevo Wilson ${ }^{3 *}$ \\ ${ }^{1}$ Senior Lecturer, Department of Town \& Country Planning, University of Moratuwa, Sri Lanka \\ ${ }^{2}$ Project Officer, SEVANATHA Urban Resource Center, Sri Lanka \\ ${ }^{3}$ Professor, Queensland University of Technology, Australia
}

\begin{abstract}
High-density urban development with mixed land uses in Sri Lankan coastal cities generate large amounts of plastic and polythene waste (PPW). The limited capacity of city councils, the deficiencies of current waste management practices and poor awareness, a significant proportion of PPW is being released into the environment, which in turn has accumulated in the marine ecosystem through canal networks. This paper analyses the current practices of PPW disposal in one such coastal region based on a sample of 579 households, 182 commercial properties, and 103 institutions. Results indicate that out of 29 tons of PPW generated in the region, around $8 \%$ was disposed into the environment in the form of landfill, burning, and discharging into water bodies. Non-parametric correlations indicate a significant correlation between reduction of PPW (waste generators), private waste collection and awareness by local media. Qualitative analysis highlights the existing limitations of current practices of PPW disposal such as non-availability of practical and cost effective alternatives (government and industries), poor awareness of PPW impacts (waste generators, media, the local council, and researchers), negative attitudes of society, law enforcement (national government and local councils) and irregular waste collection of local councils.
\end{abstract}

\section{Introduction}

In Sri Lanka, around 70 per cent of urban population and 80 per cent of its economic infrastructure networks [1] are concentrated in coastal cities (i.e. Colombo, Dehiwala, Mt. Lavinia, Galle, Matara, Kalutara, Trincomalee, Batticaloa, Negombo, etc). Also, all five (05) proposed metro regions in the national physical planning policy are laid in the coast [2]. Around 2.7 million of urban population in these cities generates about 0.75 $\mathrm{kg} / \mathrm{person} / \mathrm{day}$ of solid waste [3] which totaling 2,026 metric tons per day.

As per Western Province Waste Management Authority, about 6 per cent of the solid waste generated in Municipal Council areas in the coast is Plastic and Polythene Waste (PPW). Recent studies have revealed that the marine plastic pollution is largely a land-based pollution source and the world has arrived at a critical point in human and environmental history [4-5]. The polythene and plastic are the most commonly found nondegradable solid waste in Municipal Solid Waste (MSW). Mismanaged polythene and plastic debris sink into the , and canals linked to lengthy beach. marine environments, and accumulate around the world. The marine organisms are facing the danger of possible entanglement, ingestion, habitat destruction and bioinvasion. The presence of debris affects the aesthetic and recreational value, causing considerable economic loss, because majority of these coastal cities' economies depend heavily on tourism and fisheries industries. With the increment of global plastic production by $5 \%$ annually, the threat of PPW on life of earth becoming massive [6].

Jambeck and others [7] have estimated quantity of plastic waste entering the ocean from 192 coastal countries around world in 2010. Accordingly, Sri Lanka ranked fifth in terms of mass of mismanaged plastic waste and accounting for marine debris of 0.24-0.64 millions of metric tons per year [8]. Major share of mismanaged PPW in coastal cities of the country enter the ocean via drains, streams, wetlands, rivers, and tides. Because larger portion of land use of coastal cities in Sri Lanka covered by wetlands, lakes, marshes

In the above context, this paper attempt to detail out the PPW mismanagement by different groups of

*Corresponding author: clevo.wilson@qut.edu.au 
stakeholders including waste generators, formal and informal collectors, recyclers, administrators, informal agencies, and waste processors. At the same time, it shows the interplay between these groups and their role in sustainable PPW management.

\section{Stakeholders and waste management hierarchy}

Within the framework of sustainable solid waste management and waste management hierarchy [9] each of the stakeholders have a role to play. The conventional waste management hierarchy could be extended by incorporating different stakeholders into each of its stages. Accordingly, the role of top stages and respective stakeholders can reduce the volume that need to dispose. Therefore the role of waste generators, market (wholesale and retail trade), Polythene and Plastic (P\&P) producers, media, national government, local councils, NGOs, collectors and parceling and packaging industry have major role in limiting PPW entering into ocean [10-11]

Similarly, authors like Shekdar [12], and White and others [13] have pointed the need of an integrated approach in solid waste management with components of technology, stakeholders, and collaborations (waste systems and production systems). However, stakeholders have central responsibility in sustainable management of PPW. Therefore, it is vital to identify their current practices, and interests in PPW management.

\section{Stakeholder and institutional behaviour in Waste Management}

The study of Ghani K. and others [14], illustrates that the public has positive intention in the waste management process. In this context, the study posits the idea that the "theory of planned behaviour (TPB)" provides a framework to understand the extent to which public perceptions and attitudes could be influenced towards effective waste management practices [15]. Accordingly, the use of psychological models helps in understanding the perceptions and reactions of the public in relation to waste separation and disposal. The application of psychological models enables to identify the factors determining the behaviours of the people to perform or not perform actions leading to effective waste management. Importantly, the study suggests that appealing to the rational thinking of the public, making the public comprehensively understand the outcomes of their behaviours, and simultaneously driving behaviours through normative social expectations, would enable to generate positive behaviours towards waste management among the public. Also, the study has identified that good moral values and situational factors (i.e. storage convenience and collection times) also encourage the active involvement of the public in waste management. Hence, the study portrays that the public is willing to participate in waste management activities if the opportunities, facilities, and knowledge on waste separation at source and waste management, are prepared and provided adequately by the respective local authorities.
At the same time, the behaviours of human actors within the institutions is discussed in the New Institutional Economics (NIE) literature highlighting the need of addressing conditions of cognition and selfinterestedness [16]. These include forms of strategic behaviour such as adverse selection, moral hazard, shirking, sub goal pursuit, and failures such as asymmetry of information and principal-agent problem [17].

\section{Laws, Policies and governance relevant to PPW in Sri Lanka}

Waste collection and disposal responsibilities are vested with the local authorities of the particular area, either a Municipal Council (as per the Municipal Councils Ordinance -1947), Urban Council (Urban Councils Ordinance - 1939) or Local Council area (Pradeshiya Sabha Act - 1987). However, major provisions related to waste management and disposal, have been made under the National Environmental Act No.47 of 1980 and Public Nuisance Ordinance.

Importantly considering the severity of the PPW problem, Government of Sri Lanka (GoSL) introduced following regulations under National Environmental Regulations No. 1 of 2017 :

- Prohibit the use of all forms of polyethylene, polypropylene, polyethylene products or polypropylene products as decoration in political, social, religious, national, cultural or any other event or occasion.

- No person shall burn openly or cause to, allow or permit the open burning of refuse or other combustible matters inclusive of plastics

- Prohibit the activities manufacture of any bag of high density polyethylene as a raw material for in country use; and sale, offer for sale, offer free of charge, exhibition or use of any bag manufactured from high density polyethylene as a raw material within the country

- Prohibit the activities of manufacture of food wrappers from polythene as a raw material for in country use; and the sale, offer for sale, offer free of charge, exhibition or use of food wrappers manufactured from polythene as a raw material within the country

- Prohibit the manufacture of polythene or any polythene product of twenty (20) microns or below in thickness for in country use; or the sale, offer for sale, offer free of charge, exhibition or use of polythene or any polythene product which is twenty (20) microns or below in thickness within the country

In terms of governance there are numerous institutions concerned with waste management at different stages, including the Ministry of Local Government and Provincial Councils, Ministry of Mahaweli Development and Environment, Ministry of Megapolis and Western Development, Central Environmental Authority, Urban Development Authority, National Solid Waste Management Support Centre, Western Province Waste Management Authority, Local Authorities, etc. Currently in Sri Lanka it is observed a 
shift from traditional formal governance to private and public sector partnership initiatives because of the deficiencies of the formal system. However, adverse selection is a common behaviour of both public and private sector institutions. As per results of this study private and informal collectors enjoy high profit margins as much as USD 60 per day per person, which is 6.6 times of per capita income per day of the country (which is unknown to the government and waste generators). At the same time, local councils in the public sector do not want to loose their waste management domain as it accounts for $21.8 \%$ of their expenditure, a significant share of recurrent revenue, external grants, and revenue from trade and industry refuse.

\section{PPW management in Dehiwala-Mount Lavinia Municipal Council area}

The geographical scope of this research is Dehiwala Mount Lavinia Municipal Council (DMMC) area, which is the second largest Municipality in Sri Lanka in terms of population and covers an extent of 2,109 hectare of land. Despite its high population density, larger portion of area of is covers by wetlands, lakes, marshes, and canals linked to $6.5 \mathrm{~km}$ stretch of coastal belt. High dense urban development with mix land uses generates a large amount of PPW. Due to limited capacity of the Municipal Council (MC), and the deficiencies of current waste management practices and poor awareness on PPW of waste generators, a significant proportion of PPW was release to the environment, which in turn gets accumulated, in the marine ecosystem through the canal network. However, there is no any research on unsustainable PPW management practices, and the causes for reference.

In the above context this research carried out a detail survey on current practices of PPW disposal in DMMC area covering 29 Municipal Wards. Main focus of this survey was on PPW generators including households, commercial properties, and institutions. At the same time, structured interviews were conducted with the all the stakeholder groups of PPW management in the DMMC area.

A sample of 579 households, 182 of commercial properties and 103 institutions were selected based on each category's proportionate distribution in the land use using stratified sampling method. However, wards which consist either wetlands, lakes, marshes, canal or coast line were allocated larger sample. Because, such wards have significant connection with marine ecosystem pollution.

Households included majority of middle-income properties (54.7\%), 23.5\% low income and $21.6 \%$ highincome groups. Commercial sample included $6 \%$ wholesale stores, $41.2 \%$ retail stores, $3.3 \%$ supermarkets, $5.5 \%$ fruits/vegetable stores, $2.2 \%$ fish/meat shops, $1.1 \%$ stationary, $23.1 \%$ food \& beverage, $3.8 \%$ hardware, $1.6 \%$ pharmacies and $12.1 \%$ other businesses. Institutions included $26.9 \%$ of schools/vocational training institutes, $11.6 \%$ hospitals/dispensaries, $25 \%$ religious places, $11.5 \%$ nurseries, $21.1 \%$ offices, and $3.9 \%$ railway stations.

Quantitative analysis addressed the questions of from where and how much PPW disposed into marine ecosystem, and causes of unsustainable PPW management practices using analysis types of descriptive statistics (frequencies) and correlations.

Qualitative data were fed into the NVivo software and analyses using cloud analysis (content analysis based on word frequency).

\section{PPW management hierarchy in DMMC area}

The PPW generation levels varied among the property types in DMMC area such as households, institutions and commercial properties. Average P\&P waste generation levels were calculated for each of these property types using the results of perception surveys and total generations estimated accordingly. Each public institution generates around $32 \mathrm{~kg}$ of PPW per week, commercial properties $13.4 \mathrm{~kg}$ per week and $4.8 \mathrm{~kg}$ per week by households. Altogether total polythene and plastic generation is estimated around 29 tons per day within the DMMC area. Figure 2 below details the hierarchical flow of PPW within DMMC, which was based on the results of perception surveys and interviews conducted with relevant stakeholders employing mass balancing approach. The responsible stakeholders in each of the stage of the hierarchy are listed in the left of figure.

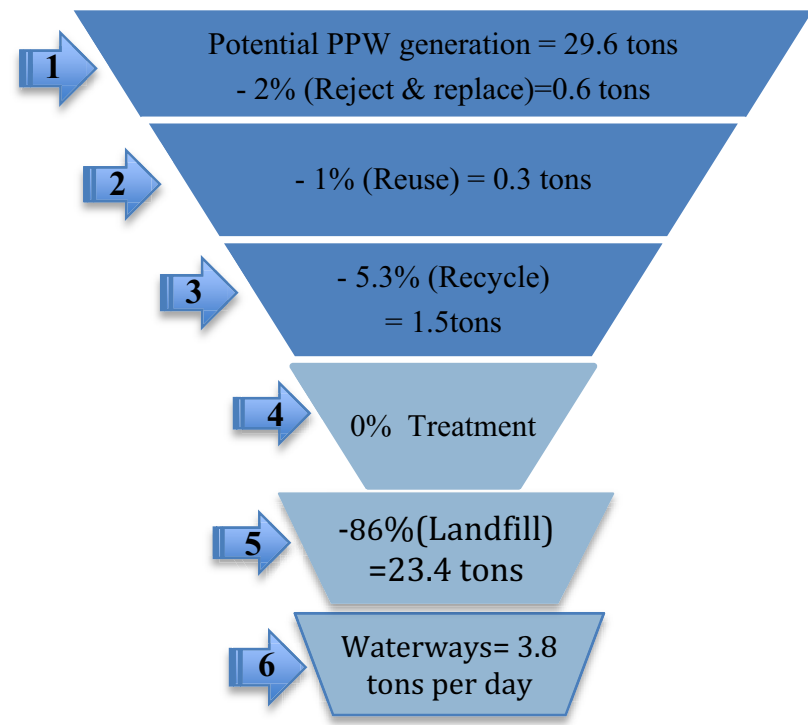

01.Waste generators, National government, Market, P\&P producers, Media, NGOs

02.Waste generators, National government, Market, Collectors, Local Council, Researchers, NGOs, industries, Media

03.Waste generators, Local Council, Researchers, Collectors, Media, NGOs

04.Collectors, processors, National government, Local Council, industries

05.Local Council, Researchers, National government, Media, Waste generators

06.Local Council, Researchers, National government, Media, Waste generators

Figure 1: Hierarchical flow of PPW in DMMC area and relevant stakeholders

\section{Stakeholder and institutional behavior in managing PPW in DMMC area}

Figure 2 and 3 below are based on the Non-parametric correlations between sets of variables used in household and commercial surveys respectively. Relationships 
which are significant at 0.05 level marked with two-way arrows, and continuous and dashed lines indicate the positive and negative relationships respectively.

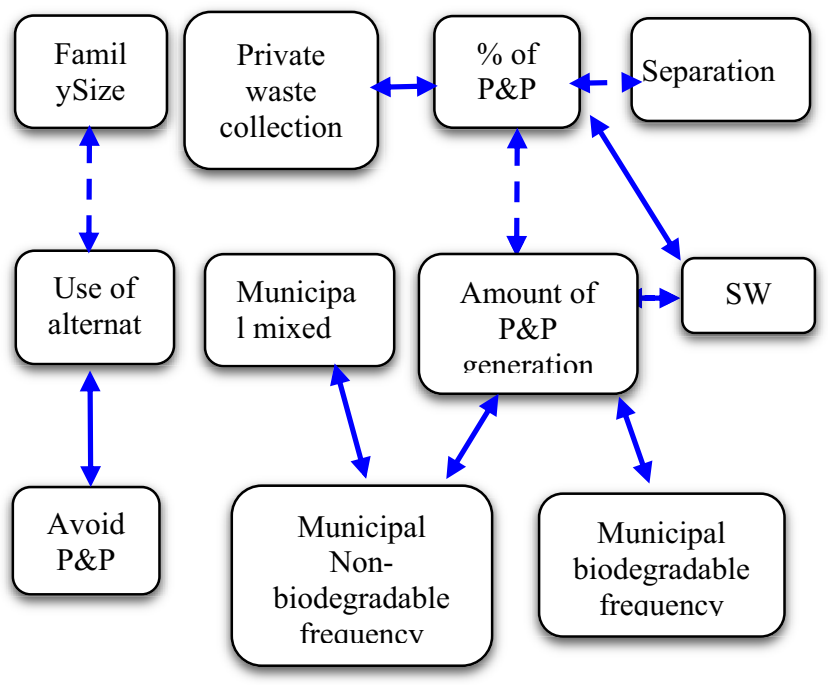

Figure 2:Relationship diagram based on household survey

According to Figure 2, when family sizes increase there is a tendency to reduce the use of alternative bags. Similar there is a negative relationship between amount of PPW generation and \% of waste which can be reduced indicating larger generators with low reduction capacities. At the same time, results show a direct relationship between municipal waste collection and PPW generation, which imply on logic of distributing larger number of trips to more PPW generating areas. Also there are signs of collecting mixed waste from households during Nonbiodegradable waste collection with a positive relationship between those two variables. On the positive side, there are positive relationships between private waste collection with \% of PPW can be reduced, and use of alternative bags to avoid polythene and plastic usage to a significant level.

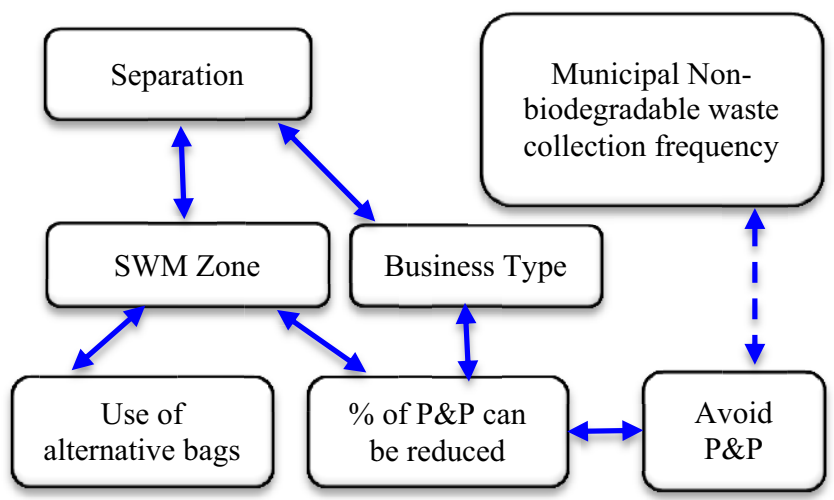

Figure 3:Relationship diagram based on household survey

As per the figure 3 separation, \% can be reduced, avoid polythene and plastic, and use of alternative bags are interconnected with business types and SWM Zones. Interestingly there is an inverse relationship between DMMC's non-biodegradable waste collection frequency and willingness to avoid polythene and plastic. This indicates that low collection frequencies causing people to avoid polythene and plastic usage or visa versa.

\section{Role of different stakeholders in managing PPW}

Polythene and plastic usage and waste generation: The market for polythene and plastic is mainly driven by the packaging industry ranging from micro-level (packing retail goods at shops) to macro-level. Although people are aware on its harmful effects; price levels, convenience and absence of close substitutes increase the attractiveness and continuous use of polythene bags. Therefore it is necessary to introduce national level regulations and governance mechanism to regulate packaging industry. At the same time industries and research institutions should develop initiatives on developing cheap and sustainable alternatives. From household level perspective, irregular shopping behaviour (daily shopping) and busy lifestyle of people increase polythene and plastic usage and limit the use of alternative bags and reuse practices. Introduction of special promotions for weekend shopping and alternative bags from the supply side, and awareness programmes on customer side could encourage positive behaviours.

Awareness: Survey results indicate the effectiveness of the local media such as awareness programmes by local authority and local initiatives. Municipal Solid Waste became hot topic for mass media only when some catastrophic event occurred like Meethotamulla garbage dump collapsed and spread of Dengue outbreaks. As suggested in the institutional survey, there is a need for grass root level awareness channeled through school children and community groups. Specially, people need to be aware on the latest rules and regulations on solid waste (i.e. prohibition of burning of polythene and plastic waste and dumping waste into the environment), because none of the survey sample mentioned on the legal consequences of PPW disposal as negative impacts.

Avoid polythene and plastic, and use of alternatives: This requires collaborative approach between consumers (demand groups), sellers (suppliers) and the government. Although there is better regulatory framework on PPW in Sri Lanka, enforcement of law is weak at the ground level. The Local Authorities and Sri Lanka Police Environment Units in each police station are responsible for enforcement of law relevant to solid waste at group level, which suffer from weaker capacity. At the same time, government should encourage new technologies and alternative products with some incentives. Suppliers also need to have initiatives to promote customer best practices like giving discounts for people who bring alternative bags and discourage polythene and plastic use by charging extra for bags. 


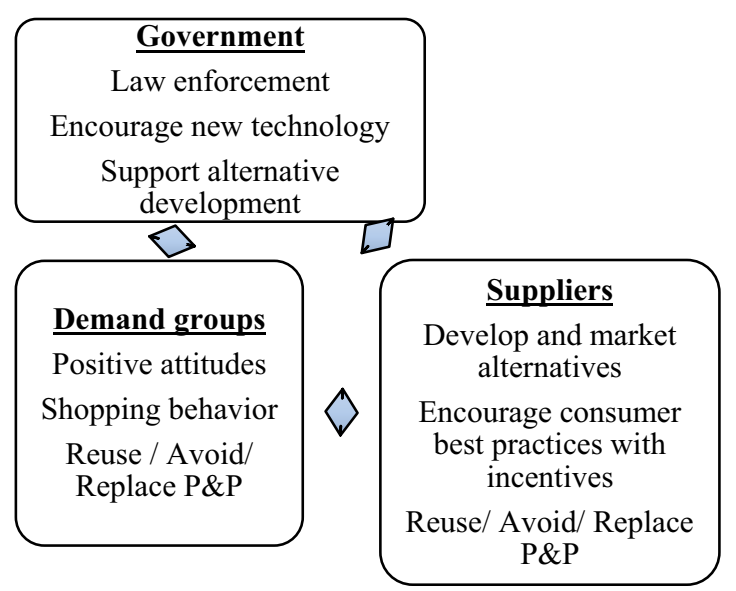

Figure 4: Collaboration for avoid polythene and plastic

Reduce: Out of three groups used for the survey, institutions records the highest per unit PPW generation. They face the challenge of regulating larger number of daily visitors and highlights the need of public attitude change towards use of public places. Commercial properties can reduce the polythene and plastic usage by using bio-degradable packing materials. It urges the national government intervention towards packging industry.

Separation: Separation is bit complex at institutions when compared with commercial properties. Because, commercial properties usually have few types of waste material (card board and polythene) which they find as nothing to separate. Following actions can be suggested to further encourage households and institutions for waste separation:

- $\quad$ Ban P\&P into public institutions (i.e. Apeksha Hospital Maharagama, Sri Lanka)

- $\quad$ Stop collecting mixed waste

- Introduction of home composting and home gardening programmes

- Introduction of Neighborhood watch programme to stop dumping waste on roadside

- $\quad$ Collecting separated waste on regular schedule

- Create market (value and collection mechanism) for all the types of sorted waste

- Establish free online trading platforms and apps to buy and sell used items

\section{Conclusions}

This study attmpted to address the questions of how, what quantities, why PPW entering into ocean from coastal cities. Similar to other coastal cities of Sri Lanka, case study of DMMC area have larger population as well as major share of landuse under marine water bodies.

Hierachy of PPW flow and mass balacing analyysis estimated the quantity of PPW entering to the ocean as 3.8 tons per day from the study area. Difficiencies within different stakeholders of PPW management have contributed this quantity.

In terms of attitude and intention, people are willing to allocate at least a little time from their daily routine for implementing a community-based SWM project. What they lack is an initiation, and participatory governance from the Municipal Council. Under the section on
Subjective Norms also, it was found that the people are driven by the society towards sustainable SWM but no enough force is given by the local authorities to facilitate public participation. As discussed in the Theory of Planned Behaviour normative or immotional (moral) motivation should be there to encourage positive behavour towards sustainable management of PPW. At the same time there should be a better integration and colloboration among different stakeholder groups.

PPW related information are vital for sustainable management of Waste. Informaiton gaps causing assemetry of information and poor awareness. Above figure contains the most frquest words of the stakeholders' sugestions on sustainable PPW management. Accordingly, households suggested on the need of better municipal waste collection, commercial property owners on cheap and practical alternatives, and institutions on positive attitudes and awareness of general public.

\section{References}

1. Department of Census \& Statistics Sri Lanka. (2013). Statistical Abstract: Department of census \& statistics Sri Lanka.

2. National Physical Planning Department Sri Lanka. (2010). National Physical Planning Policy and Plan Sri Lanka 2030. Retrieved 03.04.2011, 2011 from National Physical Planning Department Sri Lanka, http://www.nppd.gov.lk/regional physical plan.html

3. Central Environmental Authority Sri Lanka. (2014). National Solid Waste Management Program in Sri Lanka. Retrieved from https://http://www.unescap.org/sites/default/files/6 C EA.pdf

4. Jambeck, J. R., Geyer, R., Wilcox, C., Siegler, T. R., Perryman, M., Andrady, A., . . Law, K. L. (2015). Plastic waste inputs from land into the ocean. Science, 347(6223), 768-771.

5. Vince, J., \& Stoett, P. (2018). From problem to crisis to interdisciplinary solutions: Plastic marine debris. Marine Policy, 96, 200-203.

6. Landon-Lane, M. (2018). Corporate social responsibility in marine plastic debris governance. Marine Pollution Bulletin, 127, 310-319.

7. Jambeck, J. R., Geyer, R., Wilcox, C., Siegler, T. R., Perryman, M., Andrady, A., . . Law, K. L. (2015). Plastic waste inputs from land into the ocean. Science, 347(6223), 768-771.

8. Jambeck, J. R., Geyer, R., Wilcox, C., Siegler, T. R., Perryman, M., Andrady, A., . . Law, K. L. (2015). Plastic waste inputs from land into the ocean. Science, 347(6223), 768-771.

9. Manaf, L. A., Samah, M. A. A., \& Zukki, N. I. M. (2009). Municipal solid waste management in Malaysia: Practices and challenges. Waste Management, 29(11), 2902-2906.

10. Ezeah, C., Fazakerley, J. A., \& Roberts, C. L. (2013). Emerging trends in informal sector recycling in developing and transition countries. Waste Management, 33(11), 2509-2519. 
11. Horen, B. (2004). Fragmented coherence: solid waste management in Colombo. International Journal of Urban and Regional Research, 28(4), 757-773.

12. Shekdar, A. V. (2009). Sustainable solid waste management: An integrated approach for Asian countries. Waste Management, 29(4), 1438-1448.

13. White, P., Dranke, M., \& Hindle, P. (2012). Integrated Solid Waste Management: A Lifecycle Inventory: Springer US.

14. Karim Ghani, W. A. W. A., Rusli, I. F., Biak, D. R. A., \& Idris, A. (2013). An application of the theory of planned behaviour to study the influencing factors of participation in source separation of food waste. Waste Management, 33(5), 1276-1281.

15. Ajzen, I. (2011). The theory of planned behaviour: Reactions and reflections. Psychology \& Health, 26(9), 1113-1127.

16. Williamson, O. E. (2000). The New Institutional Economics: Taking Stock, Looking Ahead. Journal of Economic Literature, 38(3), 595-613.

17. Kneese, A. V., \& Bower, B. T. (2013). Managing Water Quality: Economics, Technology, Institutions (Vol. 6): Resources for the Future. 